\title{
Impact of instant controlled pressure drop pre-treatment on solvent extraction of edible oil from rapeseed seeds
}

\author{
Tamara Allaf ${ }^{1,2, \star}$, Frédéric Fine ${ }^{3}$, Valérie Tomao ${ }^{1}$, Cuong Nguyen ${ }^{4}$, Christian Ginies ${ }^{1}$ and Farid Chemat ${ }^{1}$ \\ ${ }^{1}$ Université d'Avignon et des Pays de Vaucluse, INRA, UMR 408, GREEN Extraction Team, 84000 Avignon, France \\ 2 ABCAR-DIC Process, 17000 La Rochelle, France \\ 3 CETIOM, 11 rue Monge, 33600 Pessac, France \\ ${ }^{4}$ Cantho University, College of technology, Cantho City, Vietnam
}

Received 22 October 2013 - Accepted 6 January 2014

\begin{abstract}
The fundamental analysis and modeling of kinetics of solvent extraction of rapeseed oil enable the quantification of the "washing" and "diffusion" steps. Both are illustrated through "starting accessibility" and "effective diffusivity", respectively. This is a relevant way to identify how to intensify and optimize the operating conditions in terms of highest yield and lowest extraction time. Using the instant controlled pressure drop (DIC) expansion as a pretreatment for the intensification of the whole unit operation, the starting accessibility ratio reached a value of $28.69 \%$ against $19.03 \%$ for the raw material. Effective diffusivity of DIC treated samples reached a value of $2.05 \times 10^{-12} \mathrm{~m}^{2} / \mathrm{s}$ instead of $0.72 \times 10^{-12} \mathrm{~m}^{2} / \mathrm{s}$ for the raw material. Regarding oil composition, predominant fatty acids in all extracted rapeseed oils are oleic acid (C18:1 n9) ranged from 57.58 to $59.03 \%$, linoleic acid (C18:2 n6) ranged from 21.23 to $21.89 \%$, and linolenic acid (C18:3 n3) ranged from 9.11 to $9.45 \%$. None of DIC treatment produced a significant variation in relative fatty acid profile.
\end{abstract}

Keywords: Extraction / rapeseed oil / kinetics / effective diffusivity / starting accessibility / instant controlled pressure-drop (DIC)

Résumé - Impact de la détente instantanée contrôlée en tant que pré-traitement pour l'extraction par solvant de l'huile de graines de colza. L'analyse fondamentale et la modélisation de la cinétique d'extraction par solvant de l'huile de colza permettent la quantification des deux étapes de «lavage» et de «diffusion », traduites respectivement par «l'accessibilité initiale» et la «diffusivité effective». Il s'agit d'un moyen pertinent en vue d'identifier les voies d'intensification et d'optimiser les conditions opératoires capables d'augmenter le rendement et de diminuer le temps d'extraction. L'expansion par détente instantanée contrôlée (DIC) est utilisée pour intensifier l'ensemble du fonctionnement à travers de plus grandes accessibilité initiale et diffusivité effective (28,69\% contre 19,03\% pour la matière première et $2,05 \times 10^{-12} \mathrm{~m}^{2} / \mathrm{s}$ au lieu de $0,72 \times 10^{-12} \mathrm{~m}^{2} / \mathrm{s}$ pour la matière première, respectivement). Les traitements DIC n'ont généré aucune modification significative du profil d'acides gras prédominants dans les huiles de colza extraites avec l'acide oléique (C18:1 n9) variant de 57,58 à 59,03\%, l'acide linoléique (C18:2 n6) variant de 21,23 à $21,89 \%$, et l'acide linolénique (C18:3 n3) variant de 9,11 à $9,45 \%$.

Mots clés : Extraction / huile de colza / cinétique / diffusivité effective / l'accessibilité initiale / détente instantanée contrôlée (DIC)

\section{Introduction}

The production of rapeseed oil has been highly developed over many years for food uses. Rapeseed seeds carry a quantity between 40 to $55 \%$ oil weight (wt $\%$ ) which contains triglycerides $97-99 \mathrm{wt} \%$, fatty acids $0.5-2 \mathrm{wt} \%$ and minor lipids 0.5-1 wt\% (Olivier and Elisabeth, 2009). Rapeseed oil is known for its high amounts of unsaturated fatty acids. The main fatty acid composition is approximately oleic acid C18:1 (61.6\%), linoleic acid C18:2 (21.7\%), linolenic acid

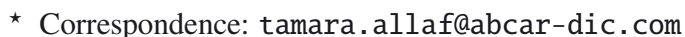

C18:3 (9.6\%), palmitic acid C16:0 (3.6\%), stearic acid C18:0 $(1.5 \%)$, and other fatty acids (3\%) (Przybylski et al., 2005).

World production of rapeseed seed amounts is about 5 million tons/year, taking the 5th place among oilseed crops (USDA, 2013). For rapeseed oil extraction, industries employ and even combine both mechanical (pre-press) and solvent extraction methods. In industrial process, residual oil content in rapeseed meal is around 2\% (Lomascolo et al., 2012).

Some factors influencing the extraction process were previously studied: the nature of the solvent (Hensarling and Jacks, 1983; Kmieciak et al., 1991), the particle size (Meziane 
et al., 2006; So and Macdonald, 1986), and the extraction conditions (temperature, pressure... ) (Fernández et al., 2012). Oil seeds were also submitted to a high pressure methanol extraction (Brühl et al., 1999; Eggers, 1985; Olivier and Elisabeth, 2009). The different factors acting on hexane extraction kinetics have been researched in the case of rapeseed (So and Macdonald, 1986) and optimal conditions for oil extraction of rapeseed and some other seeds were also tested (Tulbentci, 1986).

The extraction of oil from rapeseed using hexane as a solvent can be described via two sequential stages: solvent "washing" and deep diffusion. The first stage concerns the oil positioned on the surface which is normally easily and quickly removed at the beginning of the extraction process (So and Macdonald, 1986). It is followed by a slow extraction of the oil from the seed by a diffusion process. So and Macdonald (1986) describe this latter process in two mechanisms: slow, unhindered diffusion of oil held in the ruptured cells in the seed; and very slow, hindered diffusion of oil held within unruptured cells in the seed.

Global intensification methodology consists in first, defining the limiting phenomena and determining what to intensify in order to improve global kinetics of the operation (Allaf et al., 2011a; So and Macdonald, 1986).

In the case of solvent extraction, the operation starts by dissolving superficial solute in the solvent. This occurs at the surface (external process of washing) and is immediately transported towards the surrounding agitated solvent medium. After this first stage, a series of successive processes takes place, reflecting the interaction between the solid initially containing the solute and the solvent provoking the separation. These successive processes include:

1. solvent diffusion within the solid matrix,

2. internal solute dissolution in the solvent: this occurs within the solvent, which has diffused within the porous solid plant matrix (internal process),

3. solute diffusion in the solvent within the solid matrix towards the surface. This can also be considered as the diffusion of external solvent within the internal mixture of solute/solvent; the specific transport of the solute within the filled-in-solvent pores must be carried out as a Fick-type diffusion process.

4. external diffusion and/or convection transfer of the solute from the surface of the solid to the external environment.

In terms of limiting processes, steps 1 and 3 seem to be the limiting process (Allaf et al., 2011a; Allaf and Allaf, 2014).

In order to overcome limiting processes, there has been an increasing demand for new extraction techniques for getting shorter extraction time, higher yields with lower consumption of organic solvent.

The application of the instant controlled pressure drop (DIC) as a texturing pretreatment prior to solvent extraction has been considered as a relevant mean to improve the technological abilities of material. This innovative process has been studied, developed, optimized and used at industrial scale for various applications like drying (Mounir et al., 2011), decontamination (Allaf et al., 2011b), direct extraction of volatile compounds (Berka-Zougali et al., 2010; Besombes et al., 2010), texturing (Allaf et al., 2013; Mounir et al., 2011) and pre-treatment for extraction of non-volatile molecules such as flavonoids (Allaf et al., 2012; Ben Amor and Allaf, 2009). DIC is a thermo-mechanical process generated by subjecting the raw material for a short time-frame to high-pressure saturated steam followed by an abrupt pressure drop towards a vacuum. This generates an autovaporization of volatile molecules, implying instant cooling and expansion of the sample.

DIC allows the structure to be more expanded with more effective washing stage and higher diffusivity while more severe DIC conditions may imply higher breaking of cell walls. DIC has allowed solvent extraction to be undertaken very efficiently in a shorter time using less solvent (Besombes et al., 2010).

In this present work, we carried out a first approach of modeling of solvent extraction kinetics in order to identify the fundamental impact of DIC treatment and grinding in the case of rapeseed seeds. The main objective is to improve process performance (in our case extraction kinetics) without modifying the fatty acid profile. In addition, the impact of DIC treatment on rapeseed oil extraction was carried out and discussed in order to optimize DIC pretreatment parameters for intensifying solvent extraction process of rapeseed oil.

\section{Materials and methods}

\subsection{Plant and chemicals}

In this study, Astrid variety of rapeseed seeds provided by the company CETIOM, with $8.69 \%$ dry basis moisture content were treated. Analytical grade $n$-hexane used as solvent; methanol, sulfuric acid and $\mathrm{NaCl}$ used for the preparation of fatty acid derivatives were all purchased from VWR International (Darmstadt, Germany).

\subsection{Experimental protocol}

Samples of untreated and DIC-treated material were coarsely ground and then extracted via $n$-hexane Soxhlet (Fig. 1). In each case, kinetic modeling and gas chromatography analysis were used as means to characterize rapeseed seed extraction in terms of functional behavior and fatty acid determination. The ISO 659-1988 norm was also performed on the raw material to have a baseline of the extraction process (Fig. 1).

\subsection{Instant controlled pressure drop reactor and protocol}

DIC lab-scale equipment from ABCAR-DIC Process company (La Rochelle, France), is a reactor with 7-L processing vessel. Thermal treatment in this vessel is achieved using saturated steam with pressure varying from $5 \mathrm{kPa}$ up to $1 \mathrm{MPa}$. An "instant" valve ensures a connection between the vacuum tank (maintained at $5 \mathrm{kPa}$ ) and the processing vessel. DIC equipment and treatment is described in several papers (Allaf et al., 2012; Berka-Zougali et al., 2010; Kristiawan et al., 2008).

For each treatment of the experimental design, $100 \mathrm{~g}$ of rapeseed seeds were processed by DIC; i.e. rapeseed seeds undergone 2 stages: high temperature/high pressure and an instant pressure drop towards a vacuum. 


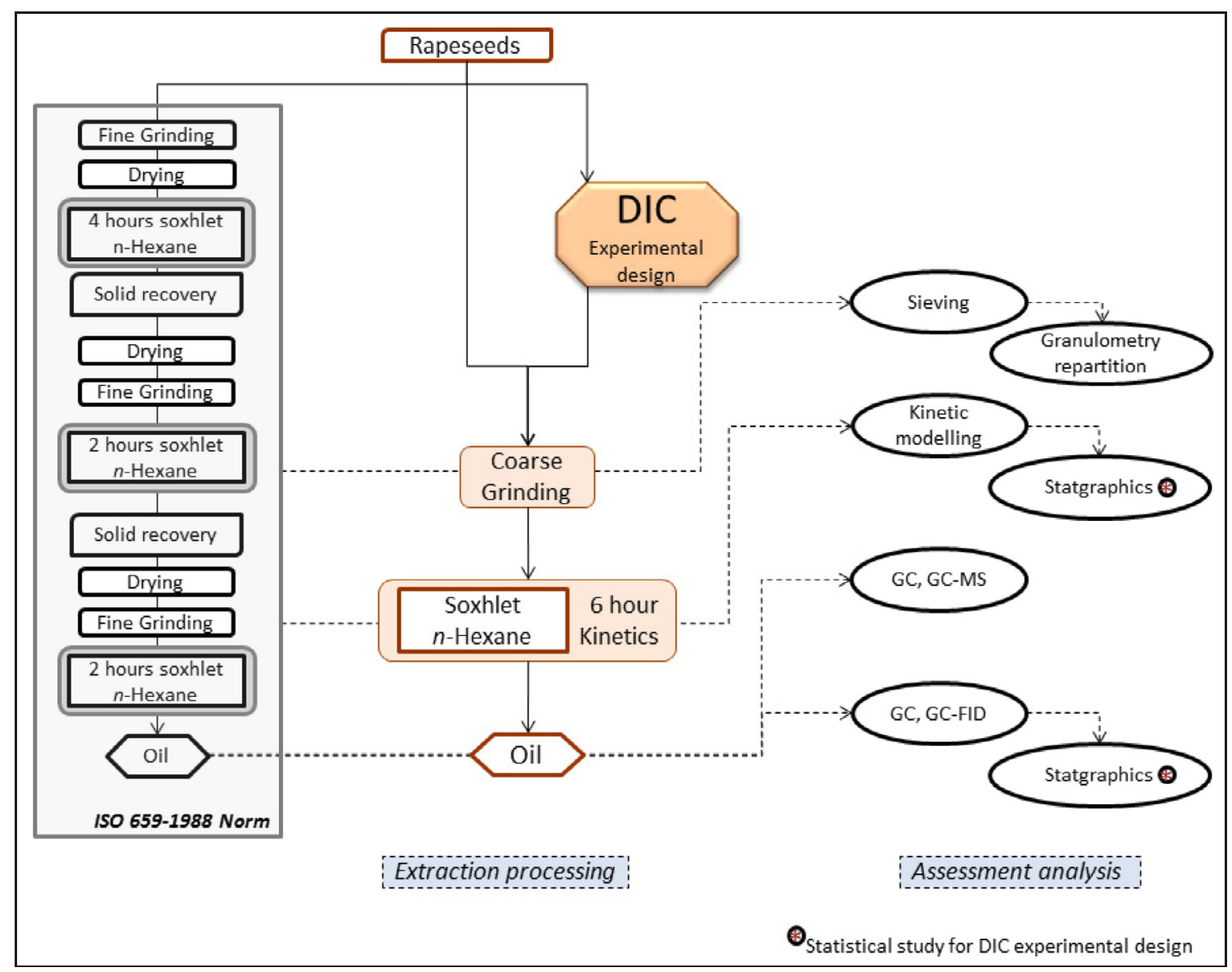

Fig. 1. Experimental Protocol.

\subsection{Soxhlet extraction apparatus and procedure}

Soxhlet extractions were performed on DIC-treated and untreated rapeseeds using $15 \mathrm{~g}$ of coarsely ground samples. The amount was transferred in a $30 \times 80 \mathrm{~mm}$ cellulose thimble and placed in the $200 \mathrm{ml}$ extraction chamber of a Soxhlet apparatus. The Soxhlet apparatus, fitted with a condenser, was placed on a $500 \mathrm{ml}$ distillation flask containing $300 \mathrm{ml}$ of hexane. Sample oil was thus extracted under $n$-hexane reflux for $6 \mathrm{~h}$ (60 siphoning). For conventional Soxhlet extraction of rapeseed oil the ISO 659-1988 norm (Standardization, 1998) procedure was carried out. The ISO-norm involved a very fine grinding.

In order to perform kinetic study, $1 \mathrm{ml}$ was withdrawn after the first, second, third and fourth siphoning then every $30 \mathrm{~min}$ until $3 \mathrm{~h}$ of extraction and then each hour. After evaporating the $n$-hexane, the samples were weighted in order to follow the extraction kinetics. Results obtained for total extraction kinetics were expressed as described hereafter:

$$
\begin{aligned}
& \% \text { Extract }(\mathrm{dm})= \\
& \frac{\text { Weight of extract obtained after extraction }}{\text { Weight of rapeseed }(\text { dry material })} \times 100 \text {. }
\end{aligned}
$$

Extractions were performed at least three times; the mean values were reported and obtained extract were analyzed via gas chromatography.

\subsection{Analytical procedures and assessments}

\subsubsection{Sieving instrument}

The sieving instrument was a vibratory sieve shaker Analysette 3 Pro from C2M technology (Florange, France). Sieving was performed for the coarse and the fine grinding with sieves of 2000-1400-1000-800-600-200-71 $\mu \mathrm{m}$ and of 800-600-560400-280-200-140-100-71 $\mu \mathrm{m}$, respectively. The amplitude of the vibration of instrument was fixed at 1.2 .

\subsubsection{Statistical and experimental design protocol}

Preliminary investigation allowed to defining a response surface methodology (RSM) with a two-factor five level $(-\alpha$; $-1 ; 0 ; 1 ; 0)$ central composite rotatable experimental design. This method was defined with: 4 factorial points $(-1 /-1$; $-1 /+1 ;+1 /-1 ;+1 /+1), 4$ star points $(-\alpha / 0 ; 0 /-\alpha ;+\alpha / 0$; $0 /+\alpha)$ and 3 repetitions: (0/0). Responses were expressed with a second order polynomial empirical model of independent variables:

$$
Y=\beta_{0}+\sum_{i=1}^{n} \beta_{i} x_{i}+\sum_{i=1}^{n} \beta_{i i} x_{i}^{2}+\sum_{i=1}^{n} \beta_{i j} x_{i} x_{j}+\varepsilon,
$$

where $Y$ was the response, $\beta_{0}, \beta_{i}, \beta_{i i}$ and $\beta_{i j}$ stand for the regression coefficients, $x_{i}$ stand for DIC operating parameters 
as independent variables, $\varepsilon$ stands for the random error, and $i$ and $j$ for the indices of the factors. RSM can be used to optimize the operating parameters by coupling various studied responses (Benoist et al., 1994).

$\alpha($ axial distance $)=\sqrt[4]{2^{N}}$. In the present case $N=2$ and $\alpha=1.4142$.

In the present study DIC operating parameters were: saturated steam pressure $(\mathrm{P})$ ranged from $0.2 \mathrm{MPa}$ to $0.7 \mathrm{MPa}$ and treatment time $(t)$ ranged from 20 to $120 \mathrm{~s}$. The responses regarding extraction kinetics and extraction yields were analyzed. Statistical treatment of obtained results was executed using the analysis design procedure of Statgraphics Plus software for Windows (version 16.0, Levallois-Perret, France).

\subsubsection{Gas chromatography}

\subsubsection{Preparation of fatty acids methyl ester derivatives}

Fatty acid methyl esters (FAMEs) were prepared according to AOCS Official method Ce 2-66 (AOCS, 1989). Samples were then filtered through a $0.2 \mu \mathrm{m}$ cellulose regenerated filter (Alltech associates, Deerfield, IL, USA) before injection.

\subsubsection{Gas chromatography analysis}

GC-MS analyses were performed by using an Agilent (Kyoto, Japan) gas chromatography. The instrument was equipped with a BD-EN14103 capillary column $30 \mathrm{~m} \times$ $320 \mu \mathrm{m} \times 0.25 \mu \mathrm{m}$ (Agilent). The velocity of the carrier gas (He) was at $33 \mathrm{~cm} \mathrm{~s}^{-1}$. Injection of $2 \mu \mathrm{l}$ of the various samples was carried out with a split mode (ratio 1:20) and the injector temperature was set at $250{ }^{\circ} \mathrm{C}$. The oven temperature increased from $50{ }^{\circ} \mathrm{C}(1 \mathrm{~min})$ to $180{ }^{\circ} \mathrm{C}$ at a rate of $20^{\circ} \mathrm{C} \mathrm{min}{ }^{-1}$, increased from $180{ }^{\circ} \mathrm{C}$ to $220{ }^{\circ} \mathrm{C}$ at a rate of $2{ }^{\circ} \mathrm{C} \mathrm{min}-1$, and then held at $230{ }^{\circ} \mathrm{C}$ for $10 \mathrm{~min}$. The mass spectra were recorded at $3 \mathrm{scan} / \mathrm{s}$ between 50 to $400 \mathrm{amu}$. The ionization mode was electron impact (EI) at $70 \mathrm{eV}$. Identification of common fatty acids was performed using the NIST'98 [US National Institute of Standards and Technology (NIST), Gaithersburg, MD, USA] mass spectral database.

GC-FID analyses were performed on an Agilent (Kyoto, Japan) gas chromatography (GC) equipped with a Flame Ionization Detector (FID). The detector temperature was $300{ }^{\circ} \mathrm{C}$. The other analytic conditions including the column type and column temperature, the injection temperature, split ratio, carrier gas and the linear velocity were the same as those of GC-MS analysis. FAMEs were identified by retention time and comparison with purified FAME standards (Sigma Co., USA).

\section{Calculation: kinetic modeling-diffusivity and starting accessibility}

In any solvent extraction achieved on plants (porous solid material), a first solvent-exchange surface interaction (washing (Fernández et al., 2012)) takes place for a short time-frame. Thus, starting accessibility $\delta X_{s}$ (expressed in $\mathrm{g}$ of extract per $\mathrm{g}$ of dry material) reveals the amount of extract obtained in very short time-frame ( $t$ near 0 ) through the convection of solvent interacting with the exchange surface. Afterward, the main part of the operation is controlled through various penetration processes of the solvent within the material (capillarity, molecular diffusivity ...). Once $t>t_{0}$ (time for achieving the washing step), the driving force of global operation is the gradient of concentration and the model can be similar to Fick's Law with an effective diffusivity $D_{\text {eff }}\left(\mathrm{m}^{2} \mathrm{~s}^{-1}\right)$ as the process coefficient (Allaf et al., 2011a; Amor et al., 2008).

1st Fick's Law (Allaf, 1982):

$$
\frac{\rho_{s}}{\rho_{d}}\left(\vec{v}_{s}-\vec{v}_{d}\right)=-D_{\mathrm{eff}} \vec{\nabla}\left(\frac{\rho_{s}}{\rho_{d}}\right) .
$$

One can assume the absence of expansion or shrinkage, i.e. $\vec{v}_{d}=0$ and $\rho_{d}=$ constant

$$
\rho_{s} \vec{v}_{s}=-D_{\text {eff }} \vec{\nabla} \rho_{s}
$$

Since the rapeseed seeds were ground (whether coarsely or finely), Crank's solution for a sphere is the most adequate:

$$
\frac{X_{\infty}-X}{X_{\infty}-X_{t_{0}}}=\sum_{i=1}^{\infty} \frac{6}{i^{2} \pi^{2}} \exp \left(-\frac{i^{2} \pi^{2} D_{\text {eff }}}{d_{p}^{2}}\left(t-t_{0}\right)\right)
$$

1st term approach of Crank's calculation is:

$$
\begin{aligned}
\frac{X_{\infty}-X}{X_{\infty}-X_{t_{0}}} & =\exp \left(-\frac{D_{\mathrm{eff}} \pi^{2}}{d_{p}^{2}}\left(t-t_{0}\right)\right) \\
{\left[\operatorname{Ln}\left(\frac{X_{\infty}-X}{X_{\infty}-X_{t_{0}}}\right)\right]^{\frac{d_{p}^{2}}{\pi^{2}}} } & =-D_{\mathrm{eff}}\left(t-t_{0}\right) .
\end{aligned}
$$

Starting accessibility: calculated value by extrapolating diffusion model to $t=0: X_{0} \neq\left(X_{i}=0\right)$

$$
X_{0}-X_{i}=X_{0}=\delta X_{s}
$$

with:

$\rho_{s}$ : apparent density of the solute within the solid matrix $\left(\mathrm{kg} \mathrm{m}^{-3}\right)$

$\rho_{d}: \quad$ apparent density of the solid dry material $\left(\mathrm{kg} \mathrm{m}^{-3}\right)$,

$v_{s}$ : velocity of the solute $\left(\mathrm{m} \mathrm{s}^{-1}\right)$,

$v_{d}$ : velocity of the solid dry material $\left(\mathrm{m} \mathrm{s}^{-1}\right)$,

$d_{p}: \operatorname{radius}(\mathrm{m})$

$X$ : amount of solute extracted at time $t\left(\mathrm{mg} \mathrm{g}^{-1}\right.$ dry material),

$X_{\infty}$ : amount of solute within the matrix ( $\mathrm{mg} \mathrm{g}^{-1}$ dry material),

$X_{t_{0}}$ : amount of solute at the end of the washing step ( $\mathrm{mg} \mathrm{g}^{-1}$ dry material),

$\delta X_{s}$ : starting accessibility ( $\mathrm{mg} \mathrm{g}^{-1}$ dry material),

$k$ : transfer coefficient $\left(\mathrm{m} \mathrm{s}^{-1}\right)$.

\section{Results and discussion}

\subsection{Extraction kinetics: study and modeling}

To identify the extraction kinetics, measurements of extracts were carried out for the different samples (untreated 


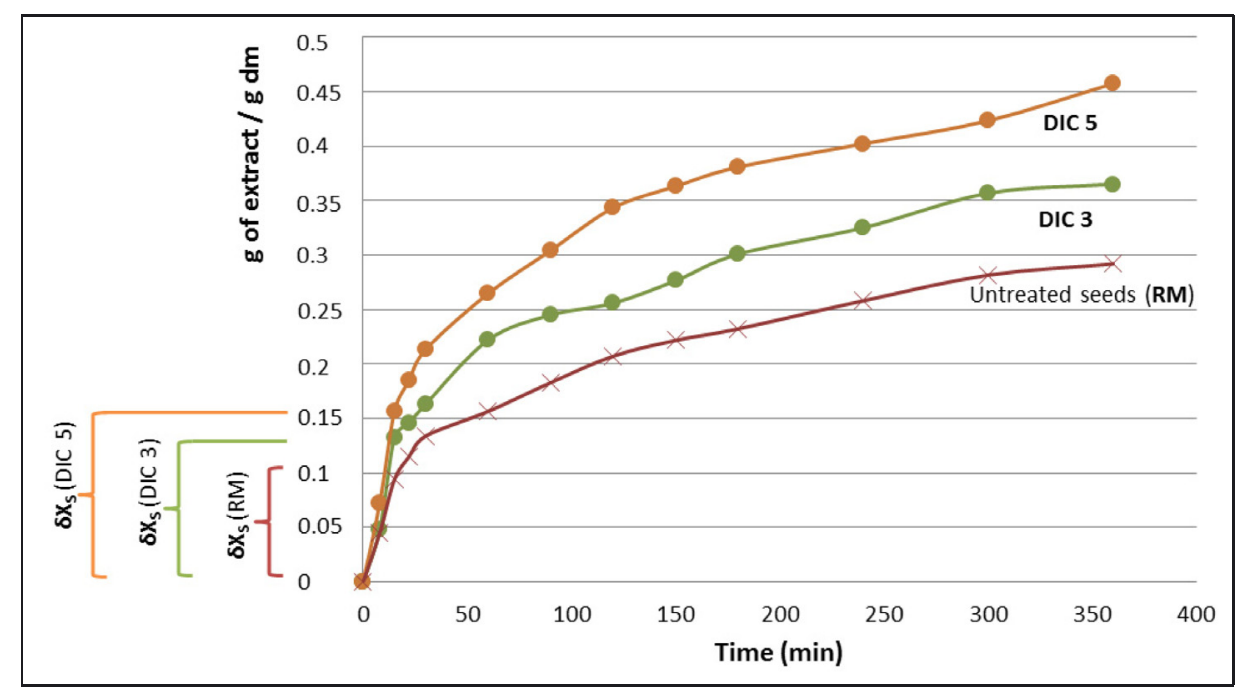

Fig. 2. Extract yield kinetics and starting accessibility $\delta X_{S}$ of rapeseed oil extraction from treated and untreated seeds.

Table 1. Starting accessibility of rapeseed extraction.

\begin{tabular}{ccccc}
\hline & \multirow{2}{*}{$\begin{array}{c}\text { Pressure } \\
\text { (MPa) }\end{array}$} & $\begin{array}{c}\text { Time } \\
(\mathrm{s})\end{array}$ & \multicolumn{2}{c}{ Starting accessibility } \\
\cline { 4 - 5 } & & & $\begin{array}{c}\text { Value } \\
\mathrm{g} / \mathrm{g} \mathrm{dm})\end{array}$ & $\begin{array}{c}\text { Ratio } \\
(\%)\end{array}$ \\
\hline DIC1 & 0.45 & 70 & 0.1240 & 23.70 \\
DIC2 & 0.7 & 70 & 0.1087 & 20.76 \\
DIC3 & 0.45 & 120 & 0.1241 & 23.71 \\
DIC4 & 0.63 & 105 & 0.1292 & 24.68 \\
DIC5 & 0.63 & 35 & 0.1501 & 28.69 \\
DIC6 & 0.45 & 70 & 0.1406 & 26.87 \\
DIC7 & 0.27 & 35 & 0.1475 & 28.19 \\
DIC8 & 0.27 & 105 & 0.1348 & 25.75 \\
DIC9 & 0.2 & 70 & 0.1444 & 27.59 \\
DIC1 & 0.45 & 20 & 0.1392 & 26.59 \\
DIC1 & 0.45 & 70 & 0.1449 & 27.68 \\
RM & - & - & 0.0996 & $19.03 \pm 1.63 \%$ \\
Norm & & - & 0.3290 & $62.87 \pm 1.40 \%$ \\
\hline
\end{tabular}

RM: Raw Material, DIC: seeds treated by DIC following the experimental design, Norm: ISO 659-1988 norm.

seeds and DIC treated). Figure 2 presents the untreated sample and two DIC pre-treated sample extract kinetics. Whatever the DIC treatment conditions, obtained kinetics during the extraction are always better than that obtained with untreated sample. Indeed, with regards to the carried out experimental design, DIC 3 and DIC 5 (Tab. 1) are the treatment inducing the weakest and the highest kinetics, respectively. Even after only 90 min extraction it was possible to obtain better extract yields with DIC 5 treatment than that obtained with untreated seeds after 6 h extraction.

To determine the values of the effective diffusivity from experimental data, equation (7) was used. The values of the starting accessibility were then obtained by extrapolating each diffusion curves till $t=0$.

To identify the impact of DIC parameters on the extraction oil, the starting accessibility $\delta X_{S}$, and the effective diffusivity $D_{\text {eff }}$ were used as response variables. The same parameters were related to that of the untreated seeds and to the ISO-norm in order to get baseline comparisons.

\subsubsection{Starting accessibility}

The starting accessibility $\delta X_{S}$ depends on the specific surface area (SSA), which for compact granules, is function of diameter $D$ and related to $1 / D$. Its value reveals the amount that is removed within the first step extraction, i.e. the "washing" stage (Fernández et al., 2012).

As shown in Table 1, DIC pretreatment systematically induced an increase of the starting accessibility $\delta X_{s}$ from $\delta X_{s}=0.0996 \mathrm{~g} / \mathrm{g} \mathrm{dm}$ for raw material to be $0.135 \pm$ $0.013 \mathrm{~g} / \mathrm{g} \mathrm{dm}$.

We can assume that the increase of $\delta X_{s}$ via DIC with an average of about $135 \%$ was caused by the enhancement of the SSA, through the possible expansion of raw materials (Ben Amor and Allaf, 2009; Iguedjtal et al., 2008; Kamal et al., 2008). In Figure 2 we can note the very low starting accessibility value of the coarsely ground untreated seeds. The slow increase of kinetic extraction (Fig. 2 untreated seeds (RM)) illustrated an extraction mainly performed via diffusion. At the opposite, the finely ground ISO-norm sample presented a very significant starting accessibility $\delta X_{s}$ compared to usual untreated seeds (62.87\% instead $19.03 \%$, respectively).

It was worth comparing the starting accessibilities of these finely ground and coarsely ground powders $\left(\delta X_{s}=32.90\right.$ instead of $9.96 \mathrm{~g} / 100 \mathrm{~g} \mathrm{dm}$, respectively), and noting their correlation with their respective Specific Surface Area (SSA) deduced from the mean diameter (360 and $1000 \mu \mathrm{m}$, respectively, Fig. 3).

The ISO-norm powder enables a better extraction via a higher starting accessibility thanks to a very fine grinding. This norm can easily be performed at laboratory scale. However, it is important to highlight that fine grinding generates real issues in industries. Hence SSA has to be enhanced via other ways (such as DIC pretreatment) than intensive grinding. 


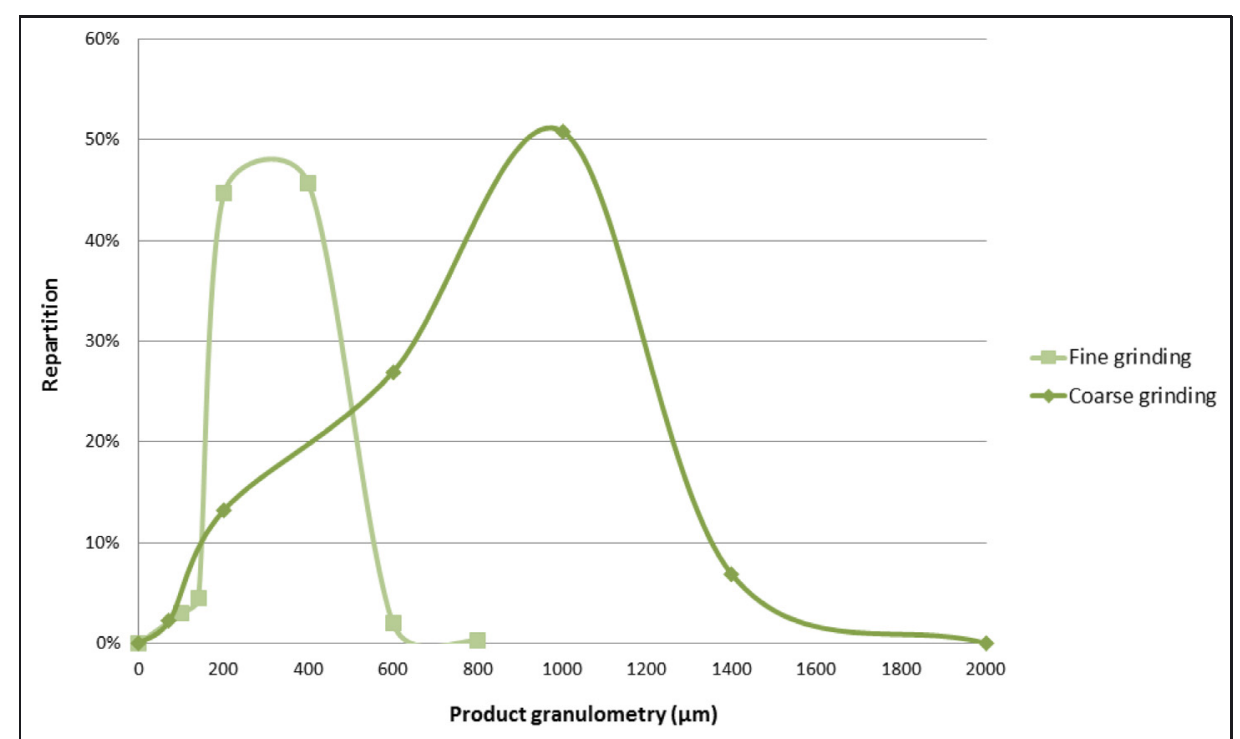

Fig. 3. Granulometry repartition of seeds ground coarsely and finely.

\subsubsection{Effective diffusivity}

To study and even optimize DIC operating parameters vis-à-vis the effective diffusivity $D_{\text {eff }}$, experimental results were analyzed using a central composite design. The mathematical relationship obtained was a polynomial empirical model representing the quantitative effect of process variables and their interactions on the measured response. The values of the coefficients of the operating parameters $P$ and $t$ were related to the effect of these variables on the response.

Pareto chart of standardized effects (Fig. 4) was calculated in order to show significant effects of all variables (linear, quadratic and interactions between variables). The vertical line represents the limit between the significant and insignificant effects regarding the response. The length of each parameter characterizes the absolute importance of the estimated effects. Moreover, the color of the squares indicates whether the effect is positive or negative. For instance the squares of the treatment time parameter is outstripping the vertical line and is in whit color i.e. negative, hence the Pareto charts revealed that the longer the treatment, the less the effective diffusivity.

It also shows that squared $t$ and squared $P$ are significant. Indeed as one can see in the main effect plot, we had an optimal point for both pressure and time. Indeed as we can see in Figure 4, if we apart from these "optimal" points we obtain a lower $D_{\text {eff }}$.

The response surfaces enabled the representation of the total effect of operative parameters. RSM optimization was used to show the impact of the operative factors in terms of effective diffusivity (Fig. 4). Saturated steam pressure injected in the treatment chamber showed an optimum when it value is average.

It was, therefore, possible to identify the highest and the quickest DIC extraction process through the operation efficiency. The optimized DIC operating conditions determined with the goal to maximize effective diffusivity was obtained with the following parameters: $0.47 \mathrm{MPa}$ and $48 \mathrm{~s}$ with $D_{\text {eff }}$ of $1.96 \times 10^{-12} \mathrm{~m}^{2} \mathrm{~s}^{-1}$ versus $0.706 \times 10^{-12} \mathrm{~m}^{2} \mathrm{~s}^{-1}$ for the usual raw material.

This established mathematical empirical model indicated hereafter:

$$
\begin{aligned}
D_{\text {eff }}= & (-0.197673+7.65688 P+0.017766 t \\
& \left.-8.50765 P^{2}-0.000183 t^{2}\right) 10^{-12} \mathrm{~m}^{2} \mathrm{~s}^{-1}
\end{aligned}
$$

with $R^{2}=83.87 \%$.

Before going any further the lack of fit test will enable to determine whether the selected model is adequate to describe the observed data or whether a more complicated model should be used. The test is performed by comparing the variability of the current model residuals to the variability between observations at replicate settings of the factors.

$$
\text { Lack-of-fit }=0.11 \text {. }
$$

Since the $P$-value for lack-of-fit in the ANOVA table is greater or equal to 0.05 , the model appears to be adequate for the observed data at the $95.0 \%$ confidence level.

In this study effective diffusivity of the extractions performed on the different material (RM, DIC1-11 and ISO-norm) were compared.

Equation (7) was used to determine the values of the effective diffusivity from experimental data (Fig. 5). The logarithmic graph generated equation with the following form $y=$ $a x+b$; a value is the effective diffusivity $D_{\text {eff }}$ in $\left(10^{-10} \mathrm{~m}^{2} / \mathrm{s}\right)$.

$$
\begin{array}{lll}
\text { DIC5 } & y=0.0188 x+0.0591 & R^{2}=97.95 \% \\
\text { RM } & y=0.00071 x+4.1595 & R^{2}=97.19 \% \\
\text { Norm } & y=0.00071 x-25.814 & R^{2}=93.37 \%
\end{array}
$$

DIC treatment systematically increased the effective diffusivity $D_{\text {eff }}$. It is very interesting here to note that both finely ground ISO-norm sample and usual coarsely ground sample, had similar values of the effective diffusivity $(0.706$ and 


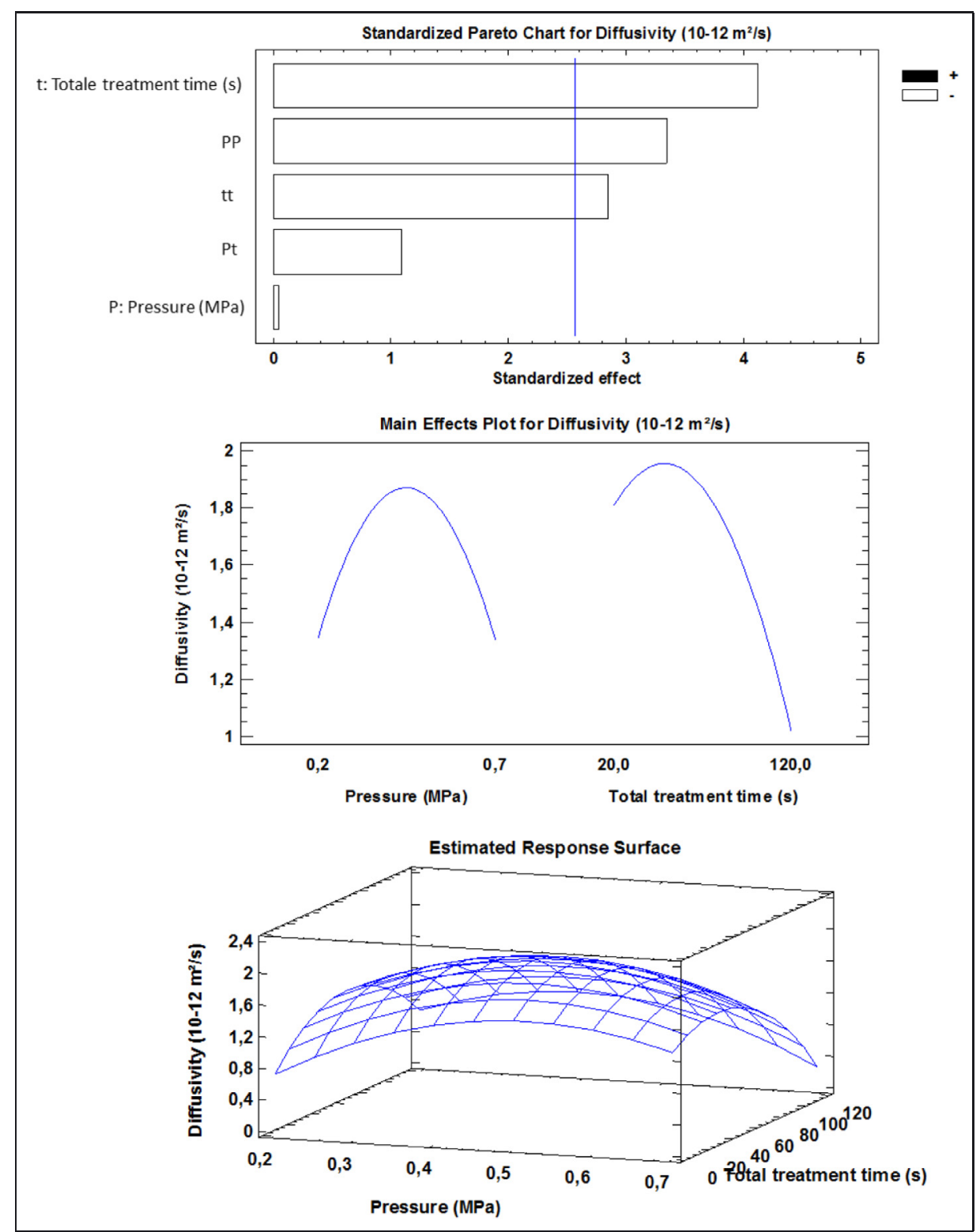

Fig. 4. Statistical modeling of rapeseed oil extraction kinetics: standard Pareto Chart, main effects plot and estimated response surface of effective diffusivity $D_{\text {eff }}$.

$0.713 \times 10^{-12} \mathrm{~m}^{2} / \mathrm{s}$, respectively), independently on the mean diameter $\left(300 \mu \mathrm{m}\right.$ and $1 \mathrm{~mm}$, respectively). $D_{\text {eff }}$ of DIC-treated samples were significantly higher. Indeed their values depending on the applied parameters were up to $1.960 \times 10^{-12} \mathrm{~m}^{2} / \mathrm{s}$. The effective diffusivity, unlike starting accessibility does not depend on the grinding of the matrix. Rapeseed seeds without pre-treatment coarsely and fine grinding had averagely the same effective diffusivity.

\subsection{Oil analysis via gas chromatography}

After establishing the extraction kinetics through weighing method, the analysis of extracts carried out by GC-MS and GC-FID using FAME method, allowed to identifying their fatty acid composition revealing the profile and total amount of extracted oil in each sample (Tab. 2).

The analysis of the FAMEs by GC-FID showed that the availability of oil yields can increase from $126 \%$ to $151 \%$ for samples treated by DIC in comparison with the availability of oil yields of untreated material (RM).

\subsubsection{Impact of DIC parameters on oil extraction yields}

To determine and optimize DIC operating parameters this time vis-à-vis the final extracted lipid yield, experimental results were analyzed using Statgraphics software. The mathematical relationship obtained was a polynomial empirical model representing the quantitative effect of process variables and their interactions on the measured response. The values 


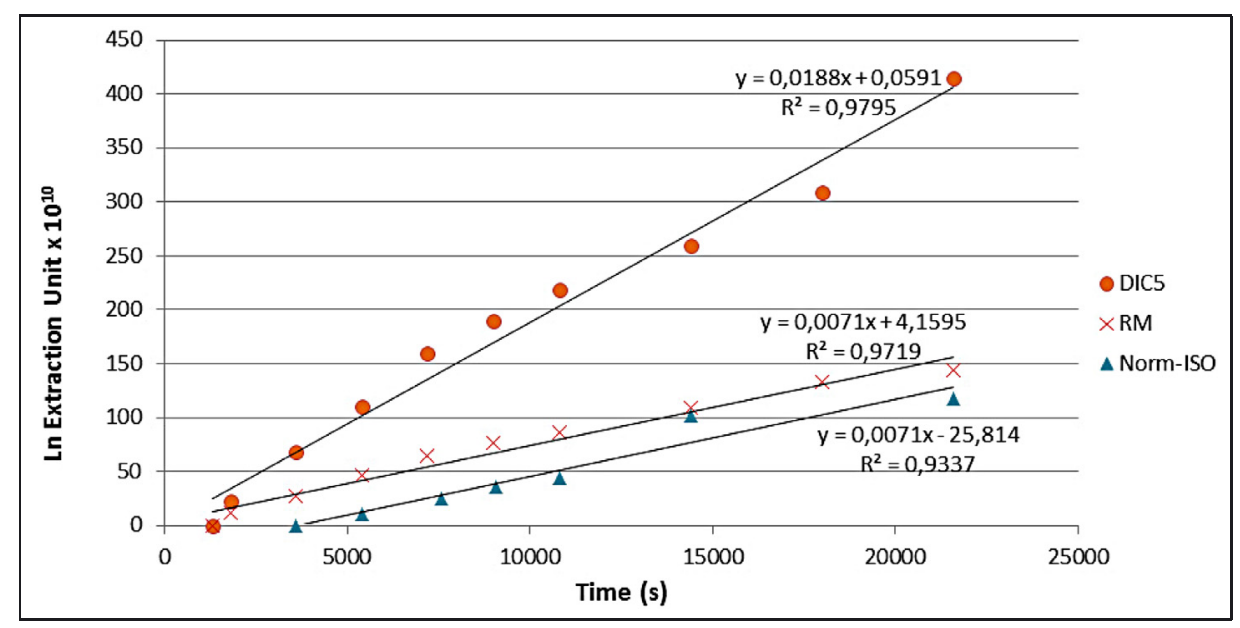

Fig. 5. Logarithmic evolution of diffusion vs. time. Ln Extraction Unit $=\left[\operatorname{Ln}\left(\frac{X_{\infty}-X}{X_{\infty}-X_{t_{0}}}\right)\right]^{\frac{d_{D}^{2}}{\pi^{2}}}$.

Table 2. Fatty acid profile (relative proportion \%) obtained via gas chromatography.

\begin{tabular}{cccccccccccccc}
\hline$\%$ & DIC1 & DIC2 & DIC3 & DIC4 & DIC5 & DIC6 & DIC7 & DIC8 & DIC9 & DIC1 & DIC1 & RM & ISO-Norm \\
\hline $\mathrm{C}_{16}$ & 3.35 & 4.21 & 4.67 & 4.28 & 4.32 & 4.27 & 4.29 & 4.29 & 4.40 & 4.30 & 4.33 & $4.16 \pm 0.06$ & $4.31 \pm 0.01$ \\
$\mathrm{C}_{16: 1 \mathrm{n} 9}$ & 0.15 & 0.17 & 0.20 & 0.18 & 0.19 & 0.18 & 0.18 & 0.18 & 0.19 & 0.19 & 0.19 & $0.18 \pm 0.01$ & $0.19 \pm 0.00$ \\
$\mathrm{C}_{18}$ & 1.19 & 1.39 & 1.51 & 1.44 & 1.43 & 1.47 & 1.49 & 1.48 & 1.54 & 1.55 & 1.51 & $1.44 \pm 0.04$ & $1.44 \pm 0.02$ \\
$\mathrm{C}_{18: \ln 9}$ & 58.87 & 58.12 & 58.04 & 58.09 & 57.58 & 58.02 & 58.56 & 58.38 & 57.96 & 57.62 & 58.23 & $57.99 \pm 0.07$ & $59.03 \pm 0.07$ \\
$\mathrm{C}_{18: 2 \mathrm{n} 6}$ & 21.60 & 21.67 & 21.23 & 21.66 & 21.79 & 21.50 & 21.55 & 21.34 & 21.48 & 21.34 & 21.54 & $21.89 \pm 0.00$ & $21.76 \pm 0.00$ \\
$\mathrm{C}_{18: 3 \mathrm{n} 3}$ & 9.32 & 9.23 & 9.16 & 9.22 & 9.45 & 9.23 & 9.17 & 9.11 & 9.17 & 9.19 & 9.26 & $9.19 \pm 0.04$ & $9.20 \pm 0.02$ \\
$\mathrm{C}_{20}$ & 0.49 & 0.50 & 0.50 & 0.51 & 0.51 & 0.52 & 0.53 & 0.52 & 0.50 & 0.53 & 0.51 & $0.53 \pm 0.00$ & $0.51 \pm 0.00$ \\
$\mathrm{C}_{20: 1 \mathrm{ln} 9}$ & 2.18 & 2.04 & 2.12 & 2.10 & 2.10 & 2.11 & 1.92 & 2.12 & 2.15 & 2.23 & 2.04 & $2.02 \pm 0.01$ & $1.76 \pm 0.01$ \\
$\mathrm{C}_{20: 2 \mathrm{n} 6}$ & 0.11 & 0.11 & 0.11 & 0.12 & 0.13 & 0.13 & 0.12 & 0.12 & 0.12 & 0.13 & 0.12 & $0.12 \pm 0.00$ & $0.10 \pm 0.00$ \\
$\mathrm{C}_{22}$ & 0.25 & 0.26 & 0.27 & 0.27 & 0.25 & 0.27 & 0.29 & 0.28 & 0.27 & 0.29 & 0.28 & $0.29 \pm 0.00$ & $0.27 \pm 0.00$ \\
$\mathrm{C}_{22: 1 \mathrm{n} 9}$ & 2.46 & 2.23 & 2.12 & 2.05 & 2.16 & 2.21 & 1.81 & 2.09 & 2.11 & 2.52 & 1.89 & $2.10 \pm 0.01$ & $1.34 \pm 0.00$ \\
SFA & 5.27 & 6.36 & 6.94 & 6.50 & 6.51 & 6.52 & 6.60 & 6.57 & 6.72 & 6.68 & 6.62 & $6.42 \pm 0.10$ & $6.53 \pm 0.04$ \\
MUFA & 63.66 & 62.55 & 62.47 & 62.42 & 62.03 & 62.53 & 62.47 & 62.76 & 62.41 & 62.56 & 62.35 & $62.29 \pm 0.17$ & $62.33 \pm 0.08$ \\
PUFA & 31.02 & 31.01 & 30.50 & 31.00 & 31.37 & 30.85 & 30.83 & 30.57 & 30.76 & 30.66 & 30.92 & $31.21 \pm 0.04$ & $31.06 \pm 0.03$ \\
Yield & 36.71 & 30.92 & 28.39 & 31.56 & 37.28 & 35.58 & 31.94 & 31.17 & 32.15 & 33.77 & 35.16 & $24.72 \pm 0.10$ & $45.02 \pm 0.06$ \\
\hline
\end{tabular}

RM: Raw Material, DIC: seeds treated by DIC following the experimental design, Norm: ISO 659-1988 norm, SFA: Saturated Fatty Acid, MUFA: Mono-Unsaturated Fatty Acid, PUFA: Poly-Unsaturated Fatty Acid, Yield ${ }_{\text {oil }}$ : extracted oil yield in g/100 g dm.

of the coefficients of $P$ and $t$ were related to the effect of these variables on the response. Statgraphics software tested the statistical significance of each effect by comparing the mean square against an estimate of the experimental error. In this case, 2 effects have $P$-values less than 0.05 , indicating that they are significantly different from zero at the $95 \%$ confidence level.

Pareto chart of standardized effects (Fig. 6) was calculated in order to show significant effects of all variables (linear, quadratic and interactions between variables). As said earlier, the vertical line represents the limit between the significant and insignificant effects regarding the response. Pareto charts revealed that the longer the treatment, the less the lipid extracted. The response surfaces enabled the representation of the total effect of each operative parameter. RSM optimization was used to show the impact of the operative factors in terms of effective diffusivity (Fig. 6).

It was, therefore, possible to identify the highest and the quickest DIC extraction process through the operation efficiency. The optimized DIC operating conditions determined with the goal to maximize effective diffusivity was obtained with the following parameters: $0.51 \mathrm{MPa}-50 \mathrm{~s}$ with $36.39 \mathrm{~g} / 100 \mathrm{~g} \mathrm{dm}$ of lipid extracted yield versus $24.72 \mathrm{~g} / 100 \mathrm{~g} \mathrm{dm}$ for the usual raw material.

The equation of the fitted model is:

$$
\begin{aligned}
\text { Yield }_{\mathrm{oil}}= & 20.6866+48.8561 P+0.16806 t \\
& -54.2845 P^{2}-0.001558 t^{2}
\end{aligned}
$$

with $R^{2}=70.86 \%$

$$
\text { Lack-of-fit }=20.28 \text {. }
$$

Since the $P$-value for lack-of-fit in the ANOVA table is greater or equal to 0.05 , the model appears to be adequate for the observed data at the $95.0 \%$ confidence level. The $R$-Squared statistic indicates that the model as fitted explains $70.86 \%$ of the variability in oil extraction yields. 


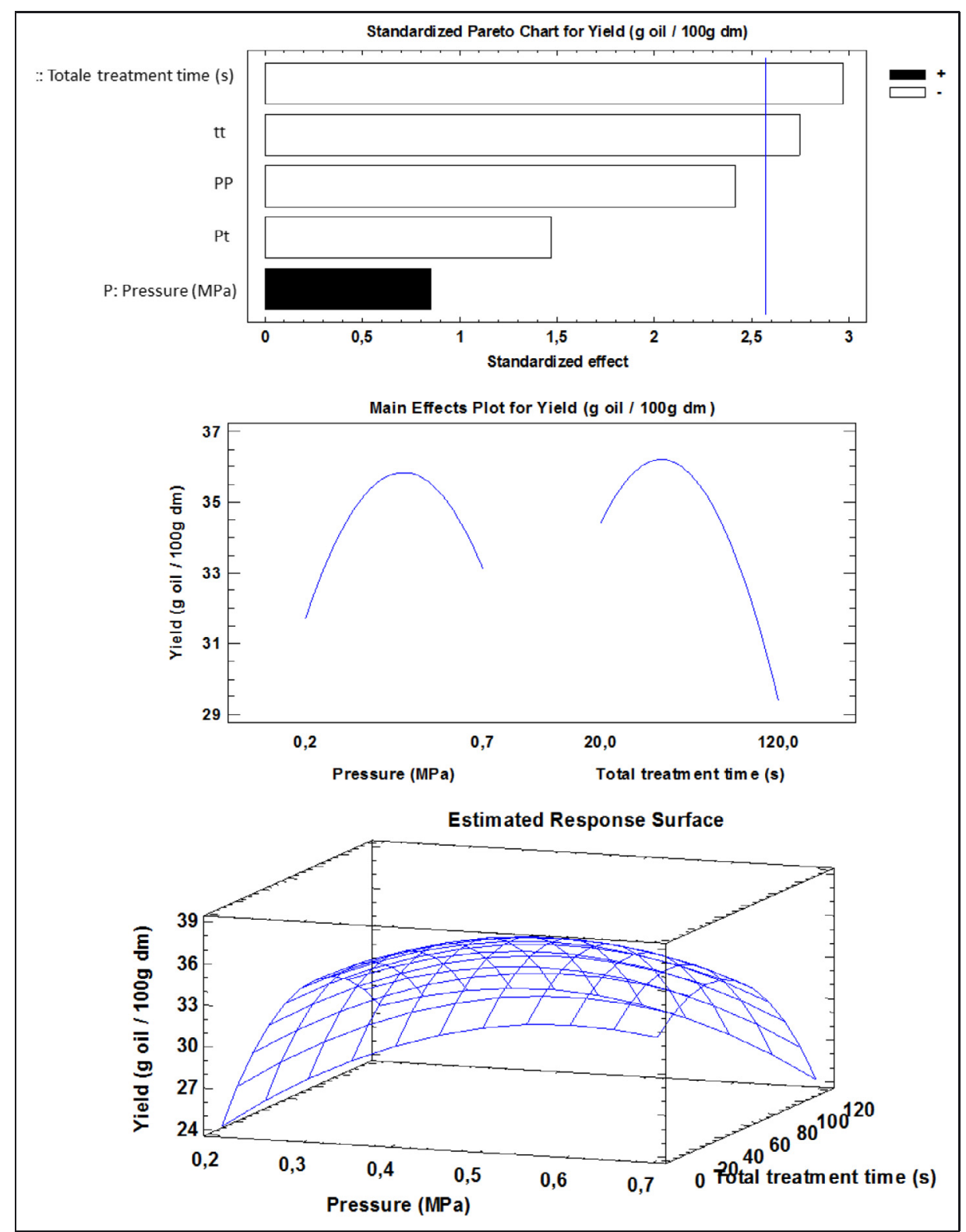

Fig. 6. Statistical modeling of rapeseed oil extraction: standard Pareto Chart, main effects plot and estimated response surface of final oil yield.

\subsubsection{Fatty acid composition (percentage level)}

Extracts were analyzed by GC-MS and GC-FID in order to identify their fatty acid composition and to compare pre-treated and untreated rapeseeds. These analyses allowed a qualitative and quantitative comparison between the different samples. The total contents of fatty acids were determined using a modified fatty acid methyl ester (FAME) method (Morrison and Smith, 1964).

Fatty acid can be divided in 3 groups: saturated fatty acids (SFA), MUFA (Mono-Unsaturated Fatty Acid) and PUFA (Poly-Unsaturated Fatty Acid). The fatty acid composition of extracted oils is presented in Table 2. Extracted rapeseed oils contain all around $60 \%$ of MUFA, $30 \%$ of PUFA and $6 \%$ of SFA.

In all the extraction of rapeseed oils we have found that there are 3 fatty acids that are predominantly present; with oleic acid (C18:1 n9) ranged from 57.58 to $59.03 \%$, linoleic acid (C18:2 n6) ranged from 21.23 to $21.89 \%$, and linolenic acid (C18:3 n3) ranged from 9.11 to $9.45 \%$.

Regarding fatty acid profile, DIC treatment did not generate degradation as shown in Table 2.

\section{Conclusion}

Rapeseed seeds were treated by instant controlled pressure-drop (DIC) at different operative parameters, as a pretreatment for solvent extraction ( $n$-hexane). Via RSM response surface methodology, the impact of DIC pre-treatment to solvent extraction on the oil extraction process showed considerable enhancement. Indeed whatever the DIC treatment conditions, oil yield and effective diffusivity, after $6 \mathrm{~h}$ of extraction, were higher than that of the untreated raw material (RM). It 
was clearly noted that, whatever the operative conditions, the DIC treatment had a strong influence on the yields and the rate of extraction process. For modeling kinetics, it was assumed the process to start by a convection stage between the solvent and the exchange surface and a second stage of diffusion within the porous solid. The first process had to be revealed through the starting accessibility, when the effective diffusivity, as well as the yields could explain the second stage.

Regarding oils quality, predominant fatty acids in all extracted rapeseed oils are oleic acid (C18:1 n9), linoleic acid (C18:2 n6) and linolenic acid (C18:3 n3). None of DIC treatment produced a modification of the fatty acid relative proportion.

\section{References}

Allaf K. 1982. Transfer phenomena and industrial applications. Beirut: Lebanese University Faculty of Science, p. 182.

Allaf T, Allaf K. 2014. Instant Controlled Pressure Drop (D.I.C.) in Food Processing. New York: Springer.

Allaf K, Besombes C, Berka-Zougali B, Kristiawan M, Sobolik V, Allaf T. 2011a. Instant Controlled Pressure Drop Technology in Plant Extraction Processes. In: Lebovka N, Vorobiev E, Chemat F, eds. Enhancing Extraction Processes in the Food Industry. Dublin. Ireland: CRC Press Taylor \& Francis Group, pp. 255302.

Allaf T, Besombes C, Mih I, Lefevre L, Allaf K. $2011 \mathrm{~b}$. Decontamination of solid and powder foodstuffs using DIC technology. In: InTech, ed. Advances in computer science and engineering. Croatia: Matthias Schmidt.

Allaf T, Tomao V, Ruiz K, Chemat F. 2012. Instant controlled pressure drop technology and ultrasound assisted extraction for sequential extraction of essential oil and antioxidants. Ultrason. Sonochem.

Allaf T, Tomao V, Ruiz K, Chemat F. 2013. Instant controlled pressure drop technology and ultrasound assisted extraction for sequential extraction of essential oil and antioxidants. Ultrason. Sonochem. 20: 239-246.

Amor BB, Lamy C, Andre P, Allaf K. 2008. Effect of instant controlled pressure drop treatments on the oligosaccharides extractability and microstructure of Tephrosia purpurea seeds. $J$. Chromatogr. A 1213: 118-124.

AOCS, A.O.C.s.S. 1989. Official Method Ce 2-66. Champaign: American Oil Chemist's Society.

Ben Amor B, Allaf K. 2009. Impact of texturing using instant pressure drop treatment prior to solvent extraction of anthocyanins from Malaysian Roselle (Hibiscus sabdariffa). Food Chem. 115: 820-825.

Benoist D, Tourbier Y, Germain-Tourb S. 1994. Plans d'expériences: construction et analyse. London: Lavoisier.

Berka-Zougali B, Hassani A, Besombes C, Allaf K. 2010. Extraction of essential oils from Algerian myrtle leaves using instant controlled pressure drop technology. J. Chromatogr. A 1217: 61346142 .
Besombes C, Berka-Zougali B, Allaf K. 2010. Instant controlled pressure drop extraction of lavandin essential oils: fundamentals and experimental studies. J. Chromatogr. A 1217: 6807-6815.

Brühl L, Matthäus B, Bernd W. 1999. Extraction of oilseeds by SFE : a comparison with other methods for the determination of the oil content. Fresenius J. Anal. Chem. 364: 631-634.

Eggers R. 1985. High pressure extraction of oil seed. J. Am. Oil Chem. Soc. 62: 1222-1230.

Fernández MB, Perez EE, Crapiste GH, Nolasco SM. 2012. Kinetic study of rapeseed oil and tocopherol extraction: Parameter comparison of nonlinear models. J. Food Eng. 111: 682-689.

Hensarling TP, Jacks TJ. 1983. Solvent extraction of lipids from soybeans with acidic hexane. J. Am. Oil Chem. Soc. 60: 783-784.

Iguedjtal T, Louka N, Allaf K. 2008. Sorption isotherms of potato slices dried and texturized by controlled sudden decompression. J. Food Eng. 85: 180-190.

Kamal IM, Sobolik V, Kristiawan M, Mounir SM, Allaf K. 2008. Structure expansion of green coffee beans using instantaneous controlled pressure drop process. Innovat. Food Sci. Emerg. Tech. 9: 534-541.

Kmieciak S, Meziane S, Kadi H, Moussaoui R. 1991. Oil extraction from olive foot cake with acidic hexane. Grasas y Aceites 42: 46-50.

Kristiawan M, Sobolik V, Allaf K. 2008. Isolation of Indonesian cananga oil using multi-cycle pressure drop process. $J$. Chromatogr. A 1192: 306-318.

Lomascolo A, Uzan-Boukhris E, Sigoillot J-C, Fine F. 2012. Rapeseed and sunflower meal: a review on biotechnology status and challenges. Appl. Microbiol. Biotechnol. 95: 1105-1114.

Meziane S, Kadl H, Lamrous O. 2006. Kinetic study of oil extraction from olive foot cake. Grasas y aceites 57: 175-179.

Morrison WR, Smith LM. 1964. Preparation of fatty acid methyl esters and dimethylacetals from lipids with boron fluoridemethanol. J. Lipid Res. 5: 600-608.

Mounir S, Besombes C, Al-Bitar N, Allaf K. 2011. Study of Instant Controlled Pressure Drop DIC - Treatment in Manufacturing Snack and Expanded Granule Powder of Apple and Onion. Drying Technol. 29: 331-331.

Olivier B, Elisabeth B. 2009. Extraction from oleaginous seeds using supercritical CO2: Experimental design and products quality. $J$. Food Eng. 92: 396-402.

Przybylski R, Mag T, Eskin NAM, McDonald BE. 2005. Rapeseed Oil, Bailey's Industrial Oil and Fat Products. John Wiley \& Sons, Inc.

So GC, Macdonald DG. 1986. Kinetics of oil extraction from rapeseed (rapeseed). Can. J. Chem. Eng. 64: 80-86.

Standardization IOf. 1998. Oilseeds - Determination of oil content (Reference method). In: Standard I, ed. Geneva, Switzerland.

Tulbentci HSG. 1986. Extraction of rapeseed, linseed, safflowerseed and tobaccoseed with a new laboratory extractor. J. Am. Oil Chem. Soc. 63: 1465-1469.

USDA. 2013. Soybeans \& Oil Crops: Rapeseed. United States Department of Agriculture Economic Research Service.

Cite this article as: Tamara Allaf, Frédéric Fine, Valérie Tomao, Cuong Nguyen, Christian Ginies, Farid Chemat. Impact of instant controlled pressure drop pre-treatment on solvent extraction of edible oil from rapeseed seeds. OCL 2014, 21(3) A301. 